\title{
Communication in Organisations as Fundamentals of Good Management or a Stumbling Block
}

Professional paper _ DOI 10.22522/cmr20160207 _ received on 29 September 2016 UDK 005.57: 334.722 _ 001.891:658.3

\section{Jadranka Škarica}

Davizo d.o.o., Zagreb, Croatia. Email: jadrankaskarica@gmail.com

\section{Ivan Tanta}

University of Applied Sciences VERN, Zagreb, Croatia. Email: ivan.tanta@vern.hr

\section{Abstract}

The environment in which businesses operate is constantly changing and managers are often forced to make decisions that would help businesses adapt to changes. In this context, communication skills are very important especially in managing change in order to increase the quality of decisions and the likelihood that the employees will be motivated for successful implementation of changes. This study will provide an overview and an analysis of communication in organisations based on the results of the survey, and it will provide recommendations on how to effectively communicate changes. Recently published studies did not address the effectiveness of communication in implementing changes using survey questionnaires. The results obtained from the survey are applicable in practice and could be used by managers and employees to ensure a more successful implementation of inevitable change and to reduce the unwanted effects if the change is not communicated effectively.

Keywords: business organisations, change management, communication, decision making, implementing change, organisational changes, restructuring processes 


\section{Introduction}

In dynamic business and living environment, managers and employees face the challenge of smaller or bigger changes almost on a daily basis. The success of implementing changes is in correlation with the internal communication in the company.

Some changes that take place have a big influence on people and businesses. They can take you by surprise although the likelihood of some changes can be anticipated with high probability. It is important to have a proactive approach to change because the success of your business may depend on your ability to adapt to change.

The environment in which companies do business is constantly changing, forcing managers to make decisions in order to build their company's capacity to adapt to changes. Regardless of the types of changes, they can often cause problems because they represent an "opportunity" and a "threat" at the same time. It is up to every person to look at change and to interpret it. Some managers are successful in translating "threat" into an "opportunity" and some managers see a "threat" in change that represents an "opportunity". This creates problems for which solutions need to be found. Instead of asking "why is something constantly changing", it is inevitable to conclude that change is constant, it happens whether it is liked or not and the key difference between those who manage change successfully and those who are less successful is in the fact that successful people deal with change and unsuccessful people deny that change took place as well as the need to change.

Successful managers recognise key problems that need to be addressed and the unsuccessful choose to tackle only minor problems. Another difference between successful and unsuccessful managers is demonstrated in their choice of who they include in communication when addressing an issue and when.

The study shows that managers are not proactive enough in managing change, especially with regard to intensity of occurring change. The most common trap that managers fall into is the lack of time. They focus on short-term operational goals and they often think that managers should not be responsible for initiating change or, if they decide to initiate change, they do not take into account the opinion of their employees. Another misconception is that only employees at equal level in the hierarchy should be taken into account when 
deciding about change management and employees at the lowest level of the organisational structure should only be informed about it and their role in implementing change.

Employees can demonstrate their reactions to the management style in the form of active resistance if the management is inclined to adopt democratic leadership style and passive resistance if the management is inclined to adopt autocratic leadership style, but this does not lead to successful change management. On the other hand, a clear "top-down" communication style, encouraging also a "bottom-up" approach to dilute solutions, is key to successful change management in most complicated situations. Even if information that the manager needs to communicate to his employees is not what they would like to hear, there is an increased tension and stress if there is a lack of information. It takes wisdom to know who to include in the process of managing change and when.

\section{The importance and role of communication skills in the change management process}

The manager's competence is best demonstrated when problems emerge. The manager's job anticipates the ability to recognise and/or initiate changes and the decision to include employees in the process of problem solving. There are two reasons for taking into account employees: to make better decisions and to be more successful in implementing decisions (Wheatley, Frieze, 2010).

Much effort has been devoted to improving communication, more than in any other field. However, Drucker (2005) emphasised the increased level of noise and difficulty to identify various discussions about communication. What is expected is most often noticed, what is hoped to be seen is seen, and what is expected to be heard is most often heard. Communication is a powerful tool if it meets the aspirations, values and purposes of the receiver. If the communication is not appropriate it will not be received and it will encounter resistance. For centuries the preferred communication style was top-down and it was focused on what management had to say (Weihrich, Koontz, 1994). However, bottom-up communication increases the quality of decision making and the probability that these decisions will be implemented. The successful process of communication anticipates well-developed listening skills, observation skills, ability to make verbal and non-verbal statements (Miljković, Rijavec, 
2007). People are different, they have different needs and values and their inner world is complex. They look at themselves and the world around them from their own perspective. It leads to misunderstanding in communication or incomplete understanding.

In every communication relationship there are changes that are likely to be obstructed by all parties involved. When a communication process is taking place in a delicate life situation, the parties involved in the process are likely to show resistance to change. The resistance happens because people like security and they prefer to stay in their comfort zone, they like stability and consistence. Most people aspire to stability because it makes them feel secure.

Communication skills could be defined as a number of choices that contribute to successful communication. If you are not pleased with your communication skills, you should establish what skills you are not satisfied with and improve them. Using skills means making choices and learning about personal responsibility in situations. The ultimate goal is to become aware which method of communication to use, when to use it and how to behave in the process of communication.

Communication skills involve a person's feelings, thinking and behaviour:

- Responsibility for people's feelings means that he/she should be in contact with his/her feelings and correlate with them if necessary;

- Responsibility for what people are thinking means that they should be making choices that will reduce thinking which causes anxiety, depression, anger and condemnation;

- Responsibility for people's behaviour means that they should behave in a way which shows others what their intentions are.

\section{Study}

\subsection{Goal and Purpose}

Due to the intensity of the initiated changes, managers should be proactive enough in managing change. The most common obstacles are lack of time due to the focus on short-term business goals, the misconception that managers should not be responsible for initiating 
change or that they should not involve the employees in change management because it is not up to them to make decisions. There is also a misconception that only employees on the same level in the hierarchy should be taken into account and the employees at the bottom of the organisational structure should only be informed about it.

Reactions of employees to such a management style can be demonstrated as active resistance if the managers have a democratic attitude and passive resistance if the management have an autocratic attitude, but the latter does not lead to successful change management. Clear top-down communication and encouraging employees to find solutions for the most complex situations is key for successful change management. This study looks at the importance and role of communication skills in managing changes in order to increase the quality of decisions and the likelihood that employees will recognise themselves as part of the solution in order to be motivated to implement change. Therefore, the topic of this study and fundamentals of this research is the analysis of the use of communication skills in the process of change management.

The goals with regard to the topic and the subject-matter of this research are the following:

GOAL 1 - to explain how the communication in small and medium-sized organisations influences the success of change implementation

GOAL 2 - to explain how the communication between the managers and employees in small and medium-sized organisations influences the motivation of employees to implement change

GOAL 3 - to explain how communication between managers and employees influences implementation of organisation restructuring and job cuts.

The operational goal is to summarise proposals for improvement of communication on a horizontal and vertical plan in order to advance the process of implementing the change.

\subsection{Hypotheses}

Looking at the intensity of changes and the growing complexity of different environmental subsystems, it becomes inevitable that one person should not be making important decisions without prior consultation with employees relevant for that area. At the same 
time it means that a decision about change management should be made by consensus or vote. Moreover, the manager should make that decision independently after consultation with employees. This will demonstrate clear authority and responsibility of the senior person responsible for solving the problem and increase the probability of making good, quality decisions as a result of consultation with other employees. At first sight it seems illogical, but for the quality of decision-making, it is necessary to involve those employees who will look at problems from different angles and clearly express their views regardless of the view of the manager.

One of the major problems identified in big organisations is that experts from multidisciplinary fields working on projects of great importance for the organisation come to an agreement with the senior management at an early stage. However, an organisation is more likely to reach good quality decisions by looking at the problem from different perspectives. When implementing recommendations, it is important that the senior person avoids the mistake of consulting only employees at the same hierarchical level. By consulting employees at different levels in the hierarchy, it will probably increase the quality of the decision and the probability that the decision will be implemented during change management. By including employees at the lower hierarchical levels into the decision-making process, the managers will additionally increase the quality of the decision because the employees are usually closer to the problem that needs finding a solution. However, very often the proposals made by employees for solving a problem have difficulties passing some hierarchical structures.

The key reason why employees are invited into the team responsible for solving a problem is because they are part of the solution, which makes implementing the decision much easier. This reduces the probability of two possible problems: that decisions are made on the managerial and not the employee level and that they are either not implemented or are implemented with difficulty because the employees at lower hierarchical levels perceive these decisions as imposed solutions. The employees who are crucial for the implementation of decisions are experts and those with the power to show active or passive resistance, but they are usually not involved in communication because managers find them difficult. However, if they get involved, the probability of making good decisions and the success of change management is more imminent. 
The following main and auxiliary hypotheses were formulated as part of this study:

Main hypothesis 1. Communication with employees from various parts of the organisational structure increases the likelihood of making better decisions, which will be ultimately implemented more successfully during change management.

Auxiliary hypothesis 1.1. There is a positive connection between the timely involvement of employees in the process of decision-making and successful implementation of change management.

Auxiliary hypothesis 1.2. There is a positive connection between involvement of employees from different levels of the organisational structure and the successful implementation of change management.

If we start from the hypothesis that people represent the most valuable resource in every organisation, then there is the question as to why managers often treat employees as computers giving them orders to execute operations. When employees are treated in such a way, their most common reaction is passive and active resistance. If there is a lack of two-way communication and readiness of senior staff to correct their decision based on feedback they receive from junior staff, there is the possibility that employees will obstruct the implementation of the decision. In the time of crisis when there is not enough time for consultation and discussion, it is logical that decisions are made by those who are familiar with priorities and who can decide what is important. However, if that is the usual pattern for implementing change then employees may be reluctant to get involved in the decisionmaking process and decide to implement decisions made by their managers. However, their first reaction could be resistance, passive if the manager has an autocratic attitude or active if the manager allows comments from employees.

Employee resistance to change comes naturally, especially if they were not part of the team which looked into the possible consequences and options of change implementation, and unless they had time to deal with different future projections. If the employees were part of the team that was deciding about change, their motivation level will grow because they were part of the solution. If they are given enough time to look at options and consequences, the employees will have an opportunity to get acquainted with what the future will bring and they will address their greatest fear ("How am I going to cope with the new circumstances?", 
“Is it going to be obvious that I don't know how to do it?” etc.). Most often, managers do not hear the fears of their employees and they do not tackle the core of the problem in the process of change implementation.

Main hypothesis 2. Clear, concrete, timely and two-way communication between the managers and employees has a positive influence on motivation of the employees to implement changes.

Auxiliary hypothesis 2.1. The employees put up active or passive resistance to change management if they were not part of the decision-making process.

Auxiliary hypothesis 2.2. The employees put up active or passive resistance to change implementation if they were informed about it too late.

Auxiliary hypothesis 2.3. The employees have fear of change if they were not involved in the process and if they were not offered more information about the change process.

Auxiliary hypothesis 2.4. There is a positive connection between the opportunity for twoway communication with the managers and motivation of employees to implement change.

Auxiliary hypothesis 2.5. There is a positive connection between the time allocated for informing the employees about the consequences of change management and motivation for successful implementation.

Main hypothesis 3. Clear and timely communication of restructuring criteria from the managers to the employees before restructuring and job cuts has a positive influence on the feeling of security of the employees and it reduces their stress level.

Auxiliary hypothesis 3.1. There is a positive, timely and clear connection of criteria for restructuring and feelings of security.

Auxiliary hypothesis 3.2. There is a negative connection between one-way communication and last minute information about dismissal and feeling of insecurity and high level of stress.

Auxiliary hypothesis 3.3. There is a negative connection between refusal to give information and dismissal criteria and high level of stress and feeling of insecurity. 


\subsection{Study Methods and Study Plan}

There is lots of discussion at present about managing change. There are lots of studies about managing change in organisations, their potential, opportunities and threats. In his work, Aleksić (2008) emphasised that organisations should take into account a strategic and active observation of their environment and change management in order to build the sustainable and competitive capability of their organisation and enable their long-term growth and sustainability. Processing the information from the survey questionnaire showed that managing organisational change is connected with building sustainable competitive ability and longevity of the organisation, and that most Croatian companies with a long tradition have embraced features of successful change management, but that employees showed less initiative to become involved in the process of change and to participate in the teams managing change.

Alfirević (2000) in his study referred to the problem of change management in large Croatian companies in order to establish their capability to adapt to big challenges in the business environment caused by Croatia's integration in the globalisation process. His conclusions show that there is insufficient capability in our big companies to implement complex organisational change, especially referring to parts of the organisational structure with a low level of capability to implement change.

The study carried out by Maslić Seršić as part of the European Commission's project Go for Change, the information collected referred to the strategies of change management implemented in Croatian companies with an emphasis on the policy of human resources development. The results show that the majority of participants in this study were conscious of the need for change management in order to achieve economic growth and success.

The study by Miloš (2016) showed that changes should be managed in an adequate way and one of the key factors influencing the success of that process is organisational culture. It has to be shaped to influence positive attitude of employees and their acceptance of change. Perkov and Radenković (2008) said that planning and managing changes, equally cultural and technological, is among the greatest challenges for present-day managers and a key part of managerial responsibility. Managing changes anticipates a systematic implementation of knowledge, technological achievements and financial resources for change which the 
managers determined as priority in achieving the key strategic goals of the organisation.

In available studies the question of efficiency of communication in implementing change was not researched using a survey questionnaire. This study showed the importance of communication skills. The main challenges are not strategies or systems or culture, they are important as many other elements, but the core of the problem is human behaviour what people are doing and the need for significant change in what they are doing (Kotter, 2002 , p. 2). This can best be achieved through efficient and quality communication in order to enable successful implementation of inevitable changes and reduce the probability of unwanted consequences if the changes are not communicated appropriately.

\subsection{Methodology}

The survey about the use of communication skills in the change management process was carried out in the period between 1 December 2015 and 1 April 2016. The survey questionnaire was structured to identify the views and experiences among the participants with regard to communication methods and problems in communication in the conditions of significant change implementation in the organisations.

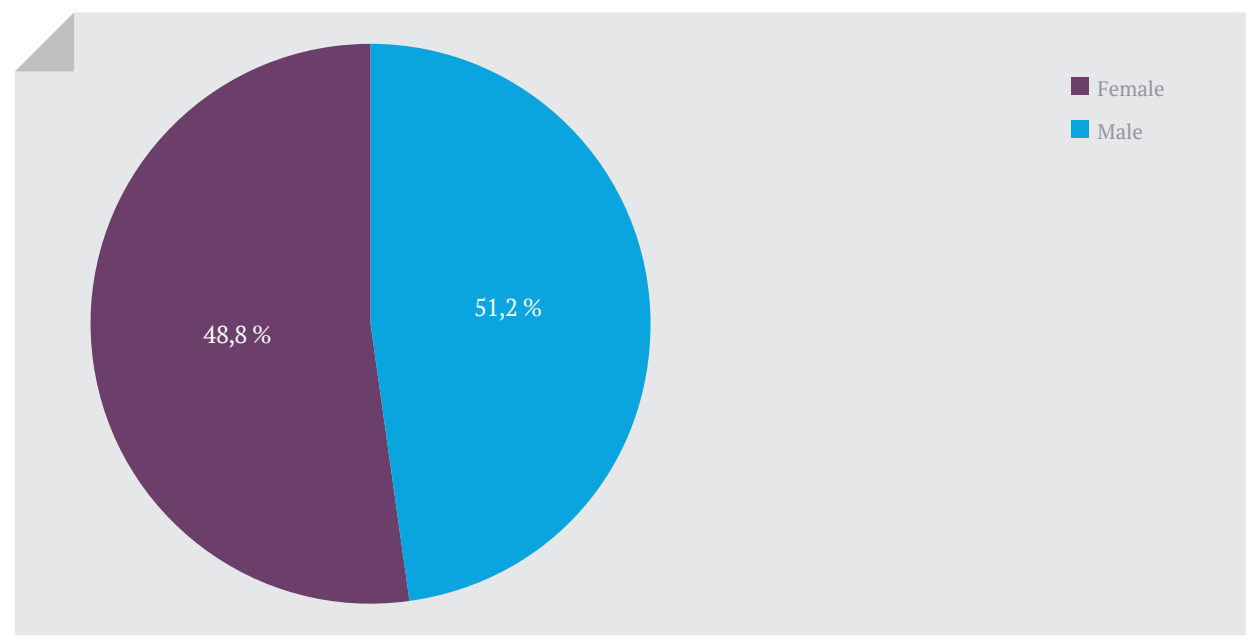

Figure 1. Respondents according to gender $(\mathrm{N}=201)$ 


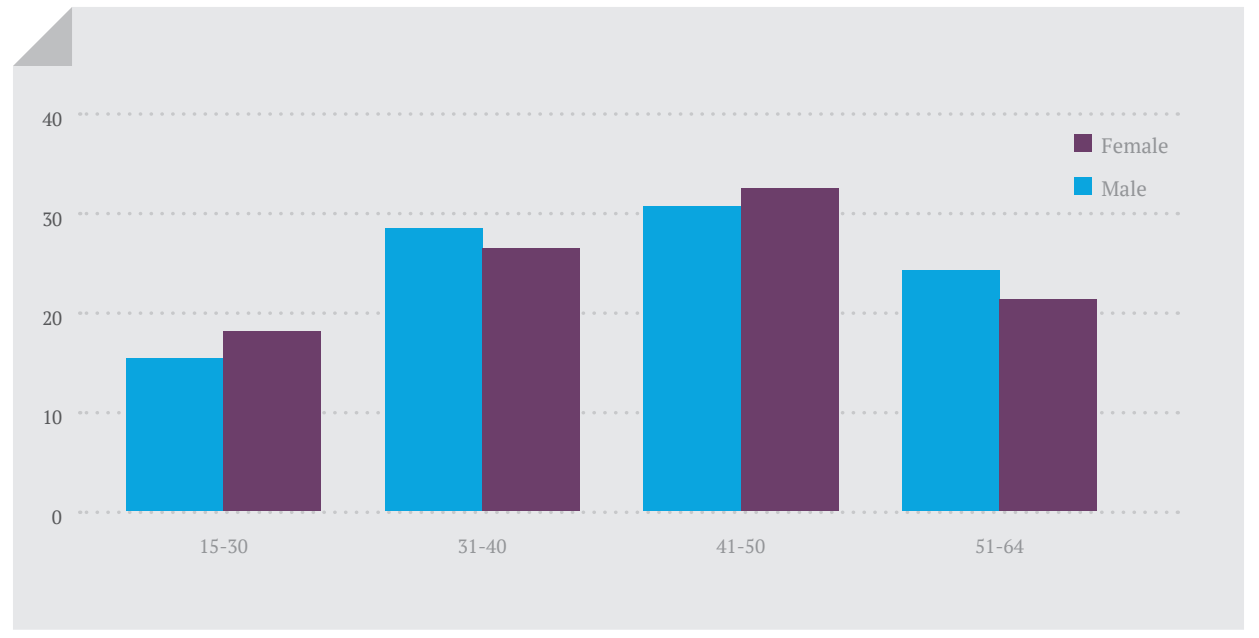

Figure 2. Male and female participants in percentages $(\mathrm{N}=201)$

The survey participants represent a diverse selection of employees with and without management responsibilities in Croatian companies with ten employees or more. The survey was carried out on a sample of 201 participants, 103 of whom were male and 98 female, aged between 19 to 64 (average age 42), employed in small, medium-sized and large companies.

Out of 201 survey participants, 95 of them belonged to low-level and middle management while 106 participants did not hold a managerial position. The online survey was used to collect data. The participants were asked to complete the online survey on a specially created web page. The survey questionnaire was carried out in the period between 11 and 29 January 2016.

The survey questionnaire used a scale from 1- 5 as well as a Likert scale to assess how questions match with proposed answers in the range from strongly agree to strongly disagree. In the survey data analysis process, descriptive statistical methods were used to calculate middle values, carry out frequency analysis, test proportion significance and average values. Some results are shown on the graphs. In addition to the survey questionnaire, the following scientific methods were used in this study:

- Method of induction and deduction for drawing conclusions

- Method of analysis and synthesis for formulating statements and conclusions into complex concepts 
- Survey questionnaire based on written data collection

- Method of comparison of different measures, methods and procedures

- Generalisation and specialisation method

- Statistical method used for statistical data analysis and use of graphs

- Method of argumentation and refutation

- Descriptive data analysis

\subsection{Results and discussion}

Descriptive data analysis showed the awareness of the need for internal communication within the organisation during the process of change because $62.7 \%$ of participants (out of 201) replied that it was the most important. The survey showed that the most common problems in "top-down" communication were dissemination of general information and the lack of clear, precise and concrete information. In "bottom-up" communication, the survey showed that the biggest problem was the lack of feedback due to fear or apprehensiveness about consequences after giving feedback.

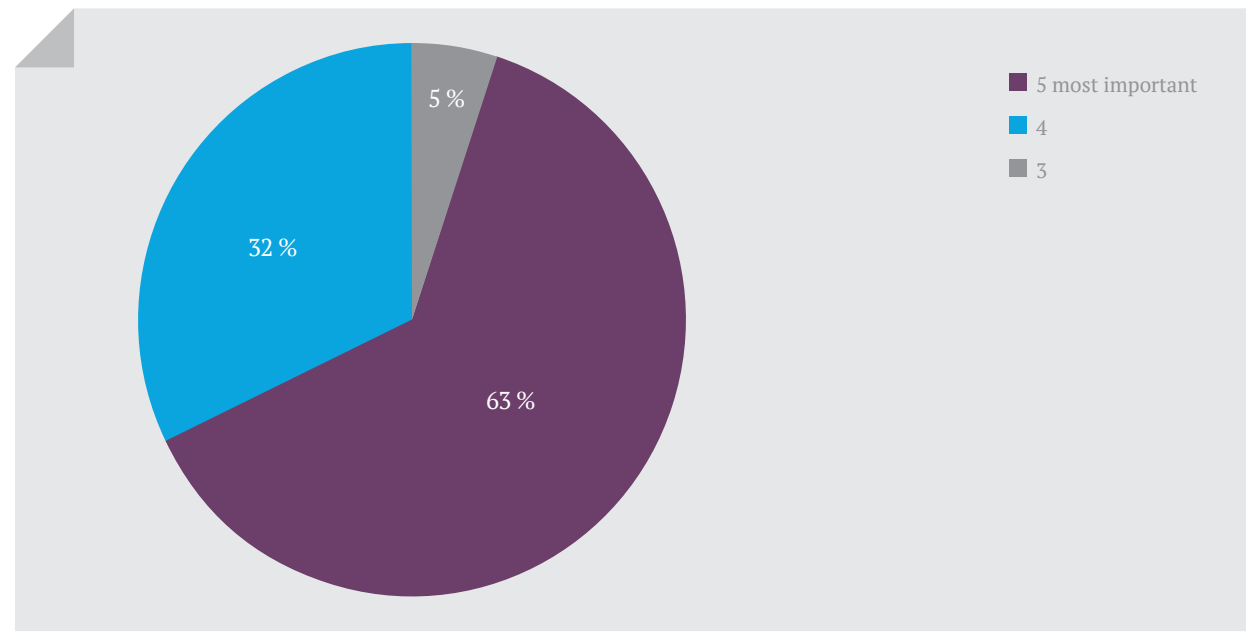

Figure 3. The importance of communication in an organisation $(\mathrm{N}=201)$ 
The survey demonstrated gender differences because female participants responded that it is very important to be included in the communication process during strategic planning (45\%) compared to $20 \%$ of male participants who responded that it is the most important.

Table 1. The importance of involvement in the communication process during strategic planning

\begin{tabular}{|c|c|c|c|c|c|c|c|c|c|c|c|c|c|}
\hline & \multirow[b]{2}{*}{ Total } & \multicolumn{2}{|c|}{ Gender } & \multicolumn{4}{|c|}{ Age - Categories } & \multicolumn{2}{|c|}{$\begin{array}{c}\text { Managerial } \\
\text { position }\end{array}$} & \multicolumn{4}{|c|}{ In charge of $n$ people } \\
\hline & & Male & Female & $19-30$ & $31-40$ & $41-50$ & 61-64 & Yes & No & 1 & $1-5$ & $6-10$ & $11 \leqslant$ \\
\hline $\mathbf{n}$ & 201 & 103 & 98 & 34 & 56 & 64 & 47 & 95 & 106 & 106 & 50 & 17 & 28 \\
\hline $\begin{array}{c}1 \text { least } \\
\text { important }\end{array}$ & 2.5 & 2.0 & 3.0 & 6.0 & 4.0 & 2.0 & & 2.0 & 3.0 & 3.0 & 4.0 & & \\
\hline 2 & 8.5 & 9.0 & 8.0 & 6.0 & 11.0 & 8.0 & 9.0 & 4.0 & 12.0 & 12.0 & 4.0 & 6.0 & 4.0 \\
\hline 3 & 23.9 & 28.0 & 19.0 & 26.0 & 21.0 & 25.0 & 23.0 & 25.0 & 23.0 & 23.0 & 20.0 & 18.0 & 39.0 \\
\hline 4 & 32.8 & 41.0 & 24.0 & 18.0 & 36.0 & 39.0 & 32.0 & 36.0 & 30.0 & 30.0 & 38.0 & 35.0 & 32.0 \\
\hline$\underset{\text { important }}{5 \text { most }}$ & 32.3 & 20.0 & 45.0 & 44.0 & 29.0 & 27.0 & 36.0 & 33.0 & 32.0 & 32.0 & 34.0 & 41.0 & 25.0 \\
\hline Average & 3.8 & 3.7 & 4.0 & 3.9 & 3.8 & 3.8 & 4.0 & 3.9 & 3.8 & 3.8 & 3.9 & 4.1 & 3.8 \\
\hline
\end{tabular}

The survey confirmed the hypotheses set in the study about the importance of communication and the communication models during the introduction of change in organisations.

The study showed that an assumption in the first hypothesis that the intensity of change and the increased complexity of various sub systems in the environment bring to unequivocal conclusion that important decisions should not be made by one person without prior consultation with employees who are responsible to implement change. Only $2.5 \%$ of participants said that it was not so important to be included in communication about decisions for implementing change with different levels of organisational hierarchy, $12.9 \%$ said that it was neither important nor unimportant while the majority (84.6\%) said that it was most important.

At the same time, this does not mean that the decision on managing change should be made by consensus or vote. On the contrary, the person responsible for implementing the change must make the decision independently after consultation with employees. This will ensure 
that the person responsible for addressing the problem is clear about his or her authority and responsibility, and the fact that the decision was made after consultation with other employees will contribute to its quality. In order to make quality decisions, it is crucial to include in the process employees with the ability to look at problems from different angles and with clarity to express their views regardless of the view of their managers.

The second hypothesis in the study that clear, concrete and timely two-way communication between the managers and employees has a positive influence on motivation of employees to implement change has also been confirmed. When employees receive no more than instructions and information about their duties, the most common reaction is passive or active resistance. Unless a small window for two-way communication is left open and if the manager shows a readiness for an accurate decision based on the feedback received from the subordinate person, the employees are likely to obstruct the implementing of the decision. The participants responded that when they were informed in a timely manner about the introduction of changes, they accepted them and gave constructive recommendations (81.6\%) or implemented them without comment (72.1\%). Participants considered imposed solutions to be the most common cause of resistance to changes, i.e. $40.3 \%$ of participants. Surprisingly, $16.9 \%$ of participants said that the cause of resistance to change was the feeling that they were neglected in the process of communicating change.

The study clearly proved the third hypothesis that the employees who were informed in a timely manner about the introduction of change, embraced the change without comment or offered concrete recommendations. Also, during various processes of restructuring and cutting jobs, it was clear that the timely involvement of employees in communication about the possible options and criteria for keeping their job as well as timely information about requalification or job cuts reduced the stress level and uncertainty because the plan was clearly defined, which contributed to the feeling of inner clarity in the situation of uncertainty imposed from outside. The participants said that in extraordinary circumstances their feeling of certainty depended on whether they were informed in a timely manner about the process of implementation (53.7\%) and whether the relations at work were supportive (45.3\%). Others thought that it was important to have an open conversation about the change (27.4\%) and support from administration and responsible authorities (8.5\%). 


\section{Conclusion}

The environment in which organisations operate is constantly changing and the managers are often forced to make decisions in order to adapt to change. For that reason, communication skills have become crucial in managing change in order to improve the quality of decisions and prospects that employees will see themselves as part of the solution and, therefore, be more motivated for successful implementation of these changes.

In this study, the survey questionnaire was used to conduct an assessment and analysis of models of communication in organisations. In the studies which were made available during the research, the question of the efficiency of communication during the implementation of change has never been supported by a survey. The results of this survey will be applicable in practise (on the management and employee levels) and will enable successful implementation of unavoidable changes as well as reduce the likelihood of unwanted consequences caused by the lack of an adequate method to communicate change.

\section{Reference List}

- Aleksić, A. (2009). Uloga upravljanja organizacijskim promjenama u izgradnji održive konkurentske sposobnosti poduzeća. Zbornik Ekonomskog fakulteta u Zagrebu, 7 (2), 37-49.

- Alfirević, N. (2000). Potencijal velikih hrvatskih poduzeća za upravljanje organizacijskim promjenama. Ekonomski pregled, 51 (11-12), 1256-1281.

- Drucker, P. (2005). Najvažnije o menadžmentu, izbor iz radova o menadžmentu Petera F. Druckera. Zagreb: M.E.P Consult.

- Kotter, J. P. (2002). The Heart of Change: Real-Life Stories of How People Change Their Organizations. Boston: Harvard Businsess School Press.

- Maslić Seršić, M. (nn). Rezultati ankete: Hrvatske tvrtke i upravljanje promjenama. Projekt Go For Change. Zagreb: Filozofski fakultet. Retrieved from: http://www.goforchange.biz/language/hr/uploads/files/projects_0/ projects_71af90ef5cd03b00faa0cc6ec814022e.pdf. December 01, 2016.

- Miloš, H. (2016). Upravljanje promjenama i organizacijska kultura hotela Villa Argentina u Dubrovniku (diplomski rad). Split: Ekonomski fakultet Split.

- Miljković, D., Rijavec, M. (2007). Organizacijska psihologija - odabrana poglavlja. Zagreb: IEP/D2.

- Perkov, D., Radenković, A. S. (2008). Upravljanje promjenama uz održivi rast hrvatskih poduzeća. Zbornik visoke poslovne škole Libertas Zagreb (pp. 30-48). Zagreb.

- Weihrich, H., Koontz, H. (1994). Menedžment. Zagreb: Mate.

- Wheatley, M., Frieze, D. (2011). Leadership in the Age of Complexity: From Hero to Host, Resurgence Magazine, 264. 


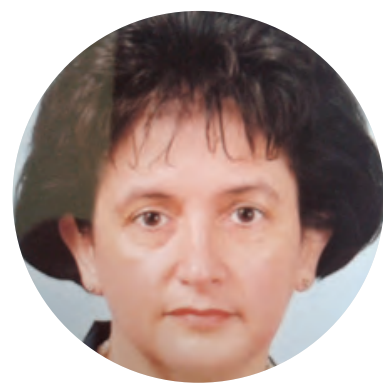

Jadranka Škarica

Jadranka Škarica was born in 1958. She graduated from the Faculty of Education and Rehabilitation Sciences, University of Zagreb and gained a master's degree in Child and Adolescent Psychiatry. After completing formal education, she trained as an autogenic training therapist in Austria with Dr Heinrich Wallnöfer. Since 1993, she works as an Autogenic Therapist, and in 2010, she founded the Croatian Society for Autogenic Training, Hypnosis and Therapy. With the support of Dr Heinrich Wallnöfer and Dr Wolf-Rainer Krause, she set up the Autogenic Training Academy in Zagreb and developed a two-year programme for Autogenic Therapists. She is the author of two books: "Kreativna sreća" (2008) and "Sveto trojstvo" (2011).

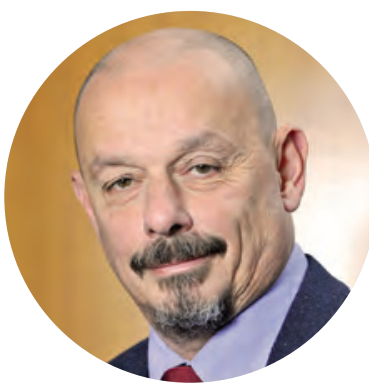

\section{Ivan Tanta}

Assoc. prof. Ivan Tanta, $\mathrm{PhD}$ was born on 25 September 1961 in Zagreb. His entire education is connected with Zagreb and the University of Zagreb. He graduated in 1980 at the Centre for Culture and Information. He gained his higher education qualifications at the Faculty of Political Science, where he graduated in 1985. During his studies, he was twice presented with the Rector's Award. He completed his master's at the Faculty of Organisation and Informatics, and he obtained his PhD from the Faculty of Philosophy, University of Zagreb. He began his career in Večernji List in various editorial positions. His career in education began as a senior lecturer in Libertas Business School. He arrived at VERN' University of Applied Sciences in 2007 as head of the Business Communications Management specialist study programme. Tanta also lectures at the University of Dubrovnik and the University of Osijek's doctoral school. Since 2014, he is a tenured college professor. 